\title{
Starting School with Special Needs: Issues for Families with Complex Support Needs as Their Children Start School
}

\author{
Sue Dockett, Bob Perry, and Emma Kearney \\ Charles Sturt University
}

\begin{abstract}
The transition to school is a time of change and expectation for children, families, and communities. It is also a time when a range of factors-both within and outside the family - influence educational experiences and outcomes. This paper reports the experiences and expectations of 24 Australian families as their children with special needs started school. Life for these families was complicated by their experiences of other factors described as complex support needs. Drawing on interview and case study data, we report issues and concerns, and examine the supports available for these families and their children across the transition to school. In analysing the data, we consider the ways in which children's special needs interact with the complex support needs of families, and consider implications of this interaction as families navigate access to support. We conclude that this interplay positions many families in ways that reinforce, rather than reduce, the difficulties encountered.
\end{abstract}

The transition to school is an important time in the lives of children, their families, and school communities (Pianta \& Cox, 1999; Westcott, Perry, Jones, \& Dockett, 2003). Families and family support play important roles in both preparing children for school (Griebel \& Niesel, 2002) and in providing continuity of experience (Pelletier \& Brent, 2002). One of the key factors in children's successful engagement with school is family involvement. However, family involvement varies considerably across different families, schools, and communities. In particular, families described as having "disadvantaged" backgrounds tend to have less involvement with schools than other families (Miedel \& Reynolds, 1999). One consequence is that while "parental involvement is a robust predictor of a child's success at school...the reality is that disadvantaged families are less likely to be involved and listened to in school environments" than other families (Bernard van Leer Foundation, 2007, p. 4).

This paper recognises family-school connections as dynamic and influenced by a range of social and cultural contexts (McTaggart \& Sanders, 2003). It considers the ways in which families described as having complex support needs, as well as the care of a child with special needs, draw upon their own resources, experiences, and circumstances to support their children during the transition to school. 
Three definitions guide this paper: transition; children with special needs; and families with complex support needs. Our definition of transition to school is based on Rogoff's (2003) broad conceptualisation of transition across the life course as times in which individuals "change their role in their community's structure" (p. 150). Educational transitions, such as the transition to school, involve changes for children as they become school students and changes for parents as they become parents of a school student. These changes bring associated changes in relationships, roles, and identities for all involved. In this paper, transition is defined as a process, beginning before children start school when families start to make decisions and seek information about school and extending beyond the actual start of school until children and families feel comfortable at school (Dockett \& Perry, 2007).

In this paper, we use the New South Wales Department of Education and Training (2010) definition of special education needs to refer to children with learning difficulties, a behaviour disorder, and/or a disability. We recognise that there is considerable variation not only in the nature of children's special education needs, but also the severity of the issues faced by children and their families (Goelman, 2008). One consequence is that the collective term, children with special needs, cloaks considerable diversity.

Families with complex support needs can be variously described as families at risk, or who are vulnerable or disadvantaged. These families often experience "multiple problems, which might be problems for the parents, for the children, or for the whole family. Examples of problems include problems relating to housing, finances, ill health, childcare, substance abuse, family violence and abuse, poor educational outcomes, truancy" (Katz, Spooner, \& valentine, 2007, p. 33). While acknowledging that such families face challenges, the term complex support needs offers two advantages over other terms. First, it suggests that problems, once identified, can be overcome. Second, it considers the interaction of problems both within the family and outside the family. We draw on the terminology of complex support needs as a means of promoting strengths-based approaches to working with families. In our experience, this terminology also promotes ongoing questioning of how families are positioned, and position themselves, as they experience the transition to school. The theoretical underpinnings of strengths-based approaches to working with families emphasise family strengths as well as needs (Cowger, 1997). In this approach, families are regarded as experts on their own lives and, with support and assistance, capable of identifying and making positive changes to their lives (Munford \& Sanders, 2003).

Much of the discussion around transition to school focuses on children's readiness (Boethel, 2004). While attention to child factors only-as opposed to consideration of these in relation to family, community, and school factors-represents a limited conceptualisation of readiness (Dockett \& Perry, 2007; Farrar, Goldfeld, \& Moore, 2007), it is certainly the case that children's skills and abilities influence their transition to school. In general, children from families with complex support needs and children with special needs are described as having lower levels of skill and ability than their peers who do not experience these conditions (Sektnan, McClelland, Acock, \& Morrison, 2010; Smart, Sanson, Baxter, Edwards, \& Hayes, 2008).

What happens at home and in communities impacts upon children's transition to school (Forget-Dubois et al., 2009). For example, experiences of poverty can have a negative effect on children's readiness for school and the ways in which they make the transition to school (Hair, Halle, Terry-Humen, Lavelle, \& Calkins, 2006). Within communities, experiences of trauma or traumatic events, such as antisocial behaviour, substance misuse, or violence and neglect, can lead to psychological as well as physiological effects (Shonkoff, Boyce, \& McEwen, 2009) that affect children's engagement in education. Conversely, communities that demonstrate strong levels of connectedness offer their members high levels of social capital that both bind the community together and provide a bridge to other communi- 
ties (Putnam, 2000). Families with complex support needs often experience challenges at both the family and community level. Such families may not feel well-placed to access support or to manage these challenges without assistance.

Our investigations of transition to school draw on ecological theory (Bronfenbrenner \& Morris, 1998) to emphasise the ways in which contexts, as well as the people within them, impact on experiences over time. Ecological models situate responsibility for an effective transition to school with all involved in the process. This broad view recognises that there are many contributors to transition experiences and that the perspectives and expectations of each of these contributors shape those experiences in some way. In these models, transition programs are opportunities for building meaningful and responsive relationships which form the basis for ongoing interactions among children, families, and schools (Dockett \& Perry, 2007; Rimm-Kaufman \& Pianta, 2000). Increasing awareness of ecological perspectives within educational provision for children with special needs is evident in some Australian contexts (Ashman \& Elkins, 2005; Petriwskyj, 2010).

\section{Transition to School for Children with Special Needs}

For many parents and children, the transition to school is a time of both excitement and anxiety. When the transition involves children with special needs, anxiety can overwhelm the excitement as parents are faced with decisions and encounter a number of barriers related to their children's educational futures (Janus, Kopechanski, Cameron, \& Hughes, 2008). Depending on the context and the nature of children's special needs, families make decisions about the type of educational setting that will be best for their child and work their way through or around barriers related to funding and support for their child (Janus et al., 2008).

Several barriers have been identified as impacting the transition to school for children with special needs, including the availability of appropriate support, both in terms of personnel and resources (Valeo, 2003). Several studies report high levels of parent dissatisfaction with the availability of school resources for their children, resulting in high levels of frustration (Hess, Molina, \& Kozleski, 2006; Janus, Cameron, Lefort, \& Kopechanski, 2007; Lake \& Billingsley, 2000), particularly with what seems like endless waiting: "waiting to see how an impairment manifests, waiting for test results, waiting for vacancies to become available," in the knowledge that "their child is missing the window of opportunity for help" (Tudball, Fisher, Sands, \& Dowse, 2002, p ii). It is of particular concern for many parents that children often start school without adequate support in place (Janus et al., 2008; Russell, 2003).

One of the major challenges in the availability of support is the discontinuity that is often experienced as children move from prior-to-school services to schools (Carlson et al., 2009). In a number of instances, support that has been available ceases, and new support is dependent on further assessments and availability. Many families find their children back on waiting lists. Rather than an unnecessary gap in support, professionals can regard times of transition as opportunities for the review of service provision (Walker et al., 1988). However, discontinuities can also lead to duplication of assessments, seemingly endless application forms and requests, often with no apparent action, and more time waiting (Wolery, 1999). Assessment processes themselves present challenges for families, as well as individual children, particularly if they are surrounded by a lack of ongoing communication, are insensitive to family experiences, or seem to lead to little action (Tudball et al., 2002).

A lack of communication among services often means children may experience little opportunity to build on prior experiences. The role of providing links between services often falls to parents who are expected to adopt the role of advocate for their child (Hess et al., 2006; Wang, Mannan, Poston, Turnbull, \& Summers, 2004). The nature and extent of the advocacy role for parents of children with special education needs can be both more complex 
and more challenging than the role required of most other parents (Ryan \& Cole, 2009). Often, it seems to be that the active involvement of parents as advocates is required to ensure that their children access appropriate support (Case, 2000; Duncan, 2003). This becomes particularly challenging for families who may feel isolated, marginalised, or who are also managing a range of other challenges. For example, Breen (2009) noted the considerable financial strain on families with a child with a disability and the additional impact of this for those experiencing financial disadvantage. In addition, the time and commitment needed to advocate for their children has implications for parents' ability to engage in the workforce as well as other activities.

While many parents adopt strong advocacy roles, they report dissatisfaction when their knowledge of their own children and their expertise are not recognised or valued (Tudball et al., 2002). Some parents report a sense of empowerment as they adopt advocacy roles; others feel overwhelmed by the need to engage in what they describe as a constant struggle for services or support (Hess et al., 2006). Successful transitions to school for children with special needs require coordination of support and a sense that family and professionals are working together.

It is recognised that multiple forms of disadvantage tend to go together for many families. For example, families of children with special needs often also experience poverty and associated challenges related to general well-being (Breen, 2009). Our investigation sought to explore what happened across the transition to school for families with a child with special needs, who also experienced complex support needs, through the following research questions: (1) What are the decision points, issues, and concerns for families with complex support needs as their children with special needs start school? and (2) What supports are required, available, and accessible for these families and their children with special needs during the year before school and the first year of school?

\section{Method}

This project was located in the state of New South Wales (NSW), Australia. In NSW, the school year commences at the end of January each year and concludes in mid-December. Within the public school system in NSW, there is provision for children with special needs to be enrolled in regular classes at their local school, support classes within some regular schools, or special schools that cater for children with more severe disabilities (New South Wales Department of Education and Training, 2010). Some independent schools also provide programs for children with special needs. Enrolment in these different types of programs is dependent on assessment of individual children and the availability of student places. Prior to starting school, children with special needs can access a range of regular or specialist services. These are available to varying degrees in different communities, but include preschool and allied health services. Financial support for families to access these services comes from several different state and federal government agencies whose roles encompass disability, health, and welfare provision. In NSW, separate agencies administer prior-to-school and school provision for children with special needs.

The research was undertaken in partnership with two organisations responsible for the delivery of early childhood intervention programs for families. Participation in this research was offered as an adjunct to involvement in existing programs to families who had a child eligible to start school. While the researchers were not privy to specific information about each family, family members disclosed a range of complex support needs encompassing chronic poverty and/or unemployment, isolation (geographic, social, cultural), experiences of violence/trauma, experiences of alcohol and/or drug misuse, and family members experiencing mental health or dependency issues. 


\section{Participants}

Forty-four families (with 46 children starting school), from a number of geographically and socio-economically diverse sites across NSW, were engaged in the project over periods ranging from 1-24 months. Of the 46 children starting school, 25 had identified special education needs. These included autism, Down syndrome, developmental delays, cerebral palsy, and problem behaviours, as well as various combinations of these and other special needs. The families ( 23 mothers, 1 grandfather) of these children with special education needs have contributed the data explored in this paper. Several other children were noted by parents either to be waiting for, or already accessing, specialist services such as speech therapy or physiotherapy.

\section{Data Collection}

Two forms of qualitative inquiry were utilised in this study: case study and grounded theory. These approaches both name the method and frame the analysis. The principles of grounded theory (Charmaz, 2008) provided the basis for the systematic and inductive generation and analysis of data. Alongside this, multiple case studies (Stake, 2008) were constructed from the same data to facilitate understanding of the transition to school for participating families and children through the comparison of cases. The selection of cases was purposive, aiming to reflect the diversity of the sample as well as opportunities for intensive study. In selecting cases, the aim was "not to represent the world, but to represent the case" (Stake, 2008, p. 142).

Teams of two researchers met regularly with family members to conduct conversational interviews about the decisions, issues, and concerns experienced by families as their children made the transition to school. Conversational interviews are outlined by BurgessLimerick and Burgess-Limerick (1998, p. 64) as a means of

\footnotetext{
gaining access to an individual's interpretations of their personal experiences....In this model of interviewing, the agenda for each interview is established interactively. A recursive process is used in which the researcher's questions build upon responses to previous questions, stories told by the same participant in previous interviews, and stories told by other participants. Each individual and situation produces a unique agenda which allows the researcher to ground the research completely in the experiences of the participants.
}

Conversational interviews were chosen in this study because they allow flexibility for the conversation between the researcher and the participant to extend beyond the limits of a particular set of questions. This helps to build strong relationships between the researcher and participant and provides opportunities for the participants to direct the conversation along the lines of their interest in the research. In this project, where the researcher and families met on several occasions, previous conversations could be revisited and it was possible to gain rich insights into the processes and circumstances that contributed to each family's decisions and concerns as their children made the transition to school. The number of meetings with individual families ranged from one to six, with over $70 \%$ of families meeting with researchers at least three times during the project. All discussions were held in locations chosen by participants and, with their permission, audio-recorded. The starting point for each conversational interview was what had been happening for the child about to start school and the family.

\section{Data Analysis}

Data analysis involved three phases. Initially, interview transcripts were read by the research team members who had conducted the conversations in order to add contextual explanation. From these readings, open codings were generated. Research team discussions 
involved constant comparison of codes, with the aim of identifying conceptual categories (Strauss \& Corbin, 1998). These discussions led to the identification of grouped themes or broad descriptors (e.g., readiness, carer expectations) that were then explored in subcategories (e.g., parent definitions of readiness, carers' own experiences of school).

The second phase involved the independent coding of transcripts, where two people each read transcripts and, based on their interpretations, allocated codes to specific pieces of data. Following this, a series of meetings was held to compare the application of the coding scheme, to identify different interpretations of the original codes, and to refine and reorganise these where necessary. These meetings were used to reach consensus in the application of codes. Once this had been achieved, two people continued to code each transcript, with the coding then checked by a third member of the research team who identified any inconsistencies. Inconsistencies were regarded as opportunities to review the codes and categories, as new and different interpretations were offered. At this point, data were entered into NVivo 8.

The final phase of analysis involved identifying connections between the codes, with the aim of describing an overarching organisational framework. Development and use of the coding framework enabled identification of issues, concerns, and family strengths across time and across the sample. Transcripts were also used to construct 13 case studies which reflected both the uniqueness of each family and some common issues experienced across the families in the larger study. Six case studies detailed the transition experiences of families with complex support needs who also had a child with special needs making the transition to school. These six case studies and the data constructed from the conversational interviews with the families of the 25 children who had identified special education needs are explored in this paper.

In reporting these data, we are conscious of the ethical obligations of researchers to treat all research participants with respect. These obligations extend to the ways research participants are represented in project dissemination. Participants already marginalised can be further marginalised by reporting that reinforces stereotypes or highlights vulnerabilities (Liamputtong, 2007). Given the theoretical underpinnings of strengths-based approaches, and the stereotypes often associated with families with complex needs and children with special education needs, we have chosen not to describe the research participants in terms of their problems or challenges only. Rather, we aim to describe participants in context, noting both challenges and strengths. As an illustration, we introduce some of the participants below:

Puno and his wife have full-time care for their granddaughter Imogen, though they are not legally recognised as her guardians. Puno originates from the Philippines but has lived in Australia for some time. Imogen has Down syndrome and will be attending a special school. Puno, aged 70, has recently retired from his job to care for his granddaughter. He has also recently undergone heart surgery. His daughter, who retains custody of Imogen but is also experiencing a number of mental health issues, is an intermittent presence in their lives. Puno describes Imogen as a wonderful girl, full of life and energy. He sees his role as that of supporting and encouraging her and hopes to live long enough to see her as a successful adult.

Barbara is a single mother of seven children aged from 2-25 years. She moved with her children to a regional area to access emergency housing. She has no family or social support and no specific support for her son Terry, aged 5, who has been diagnosed with oppositional defiance disorder, possibly with ADHD. Barbara is not working and finds it difficult to socialise or support her other children because of Terry's behaviour. Barbara has committed to supporting Terry in whatever ways are possible. Terry started school on a restricted enrolment, attending school for a few hours only each day. Barbara has foregone work opportunities to be on call in the event of problems at school, which result in her collecting Terry as soon as possible.

Andrea, her husband John, and five boys live in a rural city. John is a truck driver and is away from home at least four nights a week. Walter is the fourth son and is about to start school. He 
has cerebral palsy. He accesses physio, occupational, and speech therapy locally, but has to travel to Sydney every 3 months to seek specialist attention. Walter recently suffered a stroke. This and his ongoing hospitalisation resulted in him developing high levels of anxiety. Andrea has ceased work to be available for Walter and an older son who also has special needs.

\section{Results}

Ninety-eight conversational interviews were conducted with the 24 families with complex support needs who also had children with special needs making the transition to school. The number of interviews ranged from one to six, with an average of three per family. The number of interviews was determined by several factors: families' ongoing willingness to be involved; availability for individual appointments; and relocation during the course of the study.

Several themes emerged from the data analysis of family decisions, issues, and concerns: the importance of choosing the 'right' school; accessing support; advocating for their children; and the impact of transition on the family, as well as the child. While these themes are explored in this paper as separate entities, they were often intertwined. For example, the nature of support available and the advocacy of parents were often linked, and the nature of the school environment was often related to the impact of transition for all involved.

\section{Choosing the Right School}

Subcategories coded under this theme included finding a match between the school and the child involved; school reputation; available enrolment options; and assessments for special provision.

A match between school and child. Families sometimes faced choices about schools, including the type-regular classes, support classes, or special school-as well as the location of the school. Most families noted the importance of choosing a school that was 'right' for their child. What was right varied for each family, but included not only the available educational supports for children, but also the location of the school, the safety of the school, and the social makeup of the school. For example, Andrea explained,

To me school entails not just going to school every day, it's who the kids play with out of school, who they're growing up with...it's not the closest school but our eldest three boys...they're there already and we want him...to be at school with them for his own confidence because I think he's really going to need them when he gets to school.

School reputation. School reputation - as reported by family, friends, and community-influenced decisions about the right school. Some families had little choice about the schools their children attended; for example, if there were limited places for children with special needs, only one local school, or limited transport options.

Several families were told that their child would not be accepted in the special school or class of their choice, often because places were limited. Options for these families included seeking enrolment at the local mainstream school, applying for enrolment at a different special school, and moving to a different area in order to access another school. Each of these options involved complex planning and negotiation. Parents were very appreciative of the support offered by staff from early childhood services, early intervention programs, and schools, but still found this to be a lengthy, complicated, and often demoralising process. The complexity of the process was increased for some families who felt that their input into the decision was not valued and that only the voices of professionals were heard:

Viu was keen for her son Miles to attend a local special school which had an autism class.

Miles was not offered a place in this school. Viu had sought advice about other possible 
placements, and, as a result, the family was in the process of moving to another suburb in order to access a different school. Viu was frustrated that there were insufficient places for students in need of special school enrolment and about the difficulties she had experienced in contacting the right people about those placements that did exist. She had resorted to working through an early intervention teacher to make appointments to visit schools because the school won't talk to just parents.

Enrolment options. The complex support needs of several families impacted their ability to seek out and pursue enrolment options. For example, when families were without transport or sufficient income to access transport, the viability of travelling to different locations was limited, and when families were reliant on public housing, the option of moving suburbs was not open to them. Family members who themselves needed regular support or treatment also had to juggle these alongside the needs of their children. However, even when the choice was limited, families were still concerned that the school be 'right' for their child.

Assessments for special provision. Enrolment in either a special school or special class required assessment of children's needs. In these assessments, parental input was reported to be minimal and professional voices dominated. Assessments were times of tension for families, with major decisions about access to specific services and educational supports based on these. While working to build up children's capabilities, parents were aware that support was most likely to be directed to those children who performed poorly on such assessments. For example, Sarah's son, Harvey, had been diagnosed with Down syndrome. Harvey was to attend the local mainstream school, hopefully with support from a teacher aide. To be eligible for this support, Harvey needed to be assessed as having at least a moderate intellectual disability. As a result of assessment, he was judged to have a severe intellectual disability. While Sarah was pleased that this made him eligible for additional support, she was upset about the process and the label:

\footnotetext{
...for his whole life we've been trying to build him up and working on his strengths and everything and then all of a sudden it's the exactly opposite, you want him to perform badly and you don't want him to do this and you have to tell them about all of his weaknesses and so it's the exact opposite to what we've been doing for the last 5 years with him.
}

In some cases, assessments led to decisions that children would not have access to additional support. For some, this meant support that had been available prior-to-school was withdrawn when children started school. This caused great angst for parents, particularly when this conflicted with previous advice or when this was perceived as a short-sighted decision with long-term implications. Many parents did not understand this process and felt powerless to challenge the decision. Others were determined to access support and sought repeated assessments. This, in itself, increased the range of tensions and anxieties for all involved.

\section{Accessing Support}

Subcategories of this theme included limits to available support; consistency of support; the positioning of parents; and financial issues.

Limits to available support. Support was often available for children with special needs as they started school, but there were limits. In general, support in the form of a teacher aide was available for children classified as having moderate or severe needs. This caused concern for parents such as Andrea, who had made three unsuccessful attempts to access additional school support for Walter who had cerebral palsy. Walter's assessment identified a range of mild disabilities; "you have to be moderate to get funding," Andrea noted. The pro- 
gressive nature of Walter's disability concerned Andrea. Staff at the school advised that when things got worse, a further application could be made. Andrea noted,

that might not be until June next year, half way through the year...at the very best he will be 6 months behind....I can't figure this whole thing out....That's the hardest thing about being mild. It's good in one way, but it's worse in another way because it's just like you're running a race and you just can't make it.

Andrea had received advice from medical staff that Walter would need ongoing additional support at school. This conflicted with the advice from educational staff. Andrea was not the only person to receive conflicting advice, as Noreen noted, "you get one [set of] information from one source but you get a different lot of information somewhere else. What do you do?"

Consistency of support. The complex support needs of some of the families were supported by different agencies and groups. Where one agency supported a parent, and a different agency supported the child with special needs, it was not unusual for families to receive conflicting advice. For example, Barbara was advised by school staff that her son could attend school for only a few hours a day as they did not have the resources to respond to his problem behaviours; for her own mental health, and to have some break, she had also been advised to send him to school full-time.

While several parents noted the positive support they had received from the chosen school, others reported both frustration and resignation at apparent inaction. For example, Puno had attended a meeting with school staff about getting access to a range of therapies for Imogen: "They say 'we'll ring you, give us your telephone number,' that's about 4 months already and nobody bothered to ring us." For these families, there was a sense that decisions were made by others and that action would only occur when others were ready. There was resignation that families alone could not provide the necessary supports, and so were reliant on professionals, including school and health staff. This meant accepting decisions made by others. Some families reported feelings of helplessness; others were spurred to greater action:

I think by the time we got to actually apply for the funding I think [school staff] had just about had enough of me. She was quite... She wasn't abrupt but she was...Like, she's taking up my time for this kind of thing, that's the impression that I got. (Andrea)

Positioning of parents. Clearly, issues of power influenced the relationships between families and professionals. In one set of interviews, three parents outlined both actions and comments that positioned them as neither knowledgeable about the education system nor about how best to help their child. It was clear to these parents that professionals did not expect them to have either the knowledge or capacity to influence decisions. However, one parent described marshalling the support of the child's doctor, and then the local Member of Parliament, to prompt action. This was done with the assistance of this parent's mother on the basis that "she had a lot of problems with the education department when we were going to school, me and my brothers. So she has had a lot of dealings with them" (Teagan).

Financial issues. For many families with complex support needs, financial issues influenced the nature and range of support accessed. Many families experienced poverty and/or chronic unemployment; some family members were unwell; many also had several children or other family members who needed assistance. Some support could be accessed for a limited time or until a financial limit had been reached. Other support was available, but only after a long wait. For some families in rural communities, mobile services provided limited local access to speech and physiotherapy. However, ongoing budgetary constraints and staff turnover in these services meant that these were neither regular enough nor sufficient to provide the needed support for many children and families. A number of parents looked for- 
ward to their children starting school as a means of accessing regular support. However, they also noted gaps in service availability, particularly between their child leaving prior-to-school settings and starting at school. This was the time that targeted early childhood programs ceased and when families had to navigate the unfamiliar landscape of school education and school education support. Many families were confused that the nature of support varied so considerably between prior-to-school and school settings, and that different assessment criteria were used to support resource allocation. Further, despite interactions with the school well before the beginning of the school year, several parents noted that what they believed to have been agreed arrangements were not in place at the beginning of the school year.

Informal support. For families, informal support was valued at critical times, such as the point of diagnosis or assessment, and during periods of transition, including the transition to school. Some of the most valued support was derived from people who had already experienced similar critical times themselves. For example, Noreen was adamant that the best support came from other parents who had experienced the challenges of seeking support for their children. She commented,

professionals are not going to necessarily come out and tell you all the information you want unless you push to find that out or you speak to other Mums who are in the same spot...it's only after you've been through it that you start getting a bit more clued up.

In one community, parents described the role of a local early intervention service that helped them develop a range of skills to support them and their children, including strategies to use in interactions with other professionals, questions to ask, as well as positive approaches to parenting. This background had helped them act as advocates for their children across the transition to school.

\section{The Advocacy Role}

Subcategories coded in this theme included the impact of the family context; previous experience in an advocacy role; and school expectations.

Family context. There were many ways families acted as advocates for their children. Some families consistently sought information about what was happening for their child; others provided information and pushed to have this accepted by the school. Often this related to the family context, parental confidence, and previous experience. In some schools, parental expertise was recognised and welcomed; in others this was not the case. This was particularly so if parents themselves were also identified as having complex support needs. In some of these cases, the family unit seemed to be positioned by professionals as impaired (Dowling \& Dolan, 2001) and incapable of providing positive support for their children. Two parents explicitly indicated that they felt they had been blamed for their child's situation.

Despite the varying attitudes towards families by others, families nevertheless undertook a range of advocacy roles. Most families regarded it as part of their role, rather than that of the education system, to find the right school for the children. This also meant that if children were not offered enrolment in the preferred school or the correct support was not in place, they felt partly to blame. Some explained that they had not filled the forms in properly, not had an assessment done in time, or not accessed the right advice. Families sometimes felt overwhelmed by what they described as a continual fight to have their children's needs addressed.

In some families with complex needs, it was possible that the children's needs were just some of the many needs to be addressed and families simply did not have the energy or resources to manage everything. Often, issues outside the family contributed to ongoing prob- 
lems. For example, some families living in violent situations or experiencing poverty did not feel they had the power to effect change, and this impacted how they responded to their own and their children's needs.

Previous experience. Several of the families with complex support needs had more than one child with special needs. The advocacy role adopted by these families was influenced by their previous experiences. Noreen noted,

\begin{abstract}
With [other son] we didn't know what help we could get so we struggled along and people told me that 'it's really your problem anyway, it's not his,' so then it got left again, thinking 'well I just have to discipline him more'...and there wasn't a lot of support until way down the track. Until finally I said I just can't cope any more, this is not right and I took him to the paediatrician and I got some help then, but that was a long time ago.... So I can see you've got to get onto it early....I think you have to push...I think it's harder for people with their first time kids. Like it was with my older son. You don't know and it's only after you've been through it that you start getting a bit more clued up. But there's no way of doing that.
\end{abstract}

School expectations. Schools expected that parents would adopt some specific roles as their children started school. Two examples illustrate different responses to these expectations. Barbara, whose son Terry commenced school with a partial enrolment, was expected to be available to collect him from school initially after 2 hours or at any time that he was being disruptive. As the school year progressed, Terry was at school for longer, but Barbara was still expected to be on immediate call. Barbara commented, "I'm happy to do it....I want to have it that way because it's really important that he gets off to a good start, or as best we can." She was disappointed that support had not been forthcoming from the school, but was reluctant to demonstrate her own need for support because of her fear:

there's always this thing in the back of your mind that if you're a parent melting down, is someone going to come along and take your children away? Like I don't want to say anything because they'll think I'm a terrible mother and take them away from me.

Andrea was finally offered some assistance for her son Walter, but this was in the form of allowing her to stay at the school each morning to act as her son's teacher aide:

I just said no. It's not going to solve anything.... Not only will it not do any good, but I've got things to do, basically. I run a house with five kids by myself so I can't sit here. It might be

OK to go one morning a week, just being the normal parent. Not the teacher's aide.

Comments from other mothers echoed the view that they were assumed to be largely responsible for their child's care.

\title{
Impact of Transition on the Family
}

Subcategories coded under this theme included changes in parental roles and the impact on siblings.

Changes in parental roles. Starting school was an emotional time for all involved. Families experienced major changes in their roles, shared responsibilities, and changes in their parenting. Several parents were looking forward to the notion that there were other people who were charged with responsibilities to care for and educate their children. Others found this shared responsibility full of challenges, partly because they felt they were being judged as parents. In some instances, the relationships between children and parents were challenged as judgements were made about what children could and could not do or should be able to do. Separation was experienced as a major challenge for both children and parents, particularly when they had shared many difficult times. The impact of not accessing 
appropriate support was also felt as an emotional drain. Andrea commented, "I was a mess after they told me 'no' because I just went 'No, you can't do this. You can't get my hopes up and then say no to me." With no other avenue to pursue, Andrea commented, "I'm so tired of fighting and trying to prove to people what is the matter with Walt."

Impact on siblings. Transition to school also affected other family members. Siblings already at school were described as adopting additional responsibilities at school to look after the child starting school, sometimes to the detriment of their own social and academic engagement at school. The efforts to get children to school also meant that in some families, younger siblings missed out on activities and experiences as parents were exhausted. Where access to services required financial commitments, younger children were sometimes withdrawn from preschool services.

\section{Interplay of Complex Support Needs and Special Education Needs}

Across the case studies and interview data, it is apparent that the interplay of complex support needs and children's special education needs positioned families in ways that reinforced, rather than reduced, the difficulties they faced. Two excerpts from case studies illustrate this:

Julie was a single mother with three adult sons, a 6-year-old son, and her daughter Maddy
who was eligible to start school. Julie experienced depression and was supported by a case
worker, a friend, and her children. She had lived in a regional city for the last 25 years and de-
scribed herself as having had poor experiences at school. Julie was unsure about Maddy's
readiness for school and sought advice from the preschool and first year of school teacher.
Their advice was contradictory, with the preschool teacher suggesting that Maddy had some
social problems, and the school teacher indicating that Maddy was ready for school. Julie was
not certain about the nature of social problems identified by the preschool teacher. Julie's case
worker recommended that Maddy start school as a strategy to alleviate some of Julie's ongo-
ing depression. Julie was concerned that sending Maddy to school was something she was
doing for herself, rather than Maddy and that Maddy would be placed in a difficult position
coping with school-something she had experienced with her older children.

Julie was confused by the contradictory advice and unsure of where to turn for more definitive advice. She was uncomfortable approaching the teachers involved, and as result, enrolled Maddy in both school and preschool with the aim of making a final decision closer to the start of school. In her actions, it would be easy for teachers to judge her as indecisive and not preparing her daughter for school and for her case worker to infer that she was not really focused on improving her own health. In addition, the anxiety she experienced could well contribute to further depression.

When Danny started school, Teagan had to cover the costs of having two children at school. With the help of a local non-profit organisation, she and her husband Anthony accessed the services of a financial planner. Having identified a disposable income of \$7/fortnight, Teagan was anxious about meeting the costs of school shirts (\$17 each) and jumpers $(\$ 40)$ as well as shoes, schoolbags, lunch, and the extra costs involved in excursions. She started saving in July for the costs of uniforms in January. When the school changed the uniform, she was upset that costs were increasing. Directing money to school expenses also meant that as a family, there was limited access to other activities. For example, the boys were unable to play soccer or other sports because of the cost involved. To increase their income, Anthony worked longer hours, and as a consequence, spent less time at home. Teagan believed that this contributed to Danny's challenging behaviour.

Teagan was an incredibly organised parent, planning well in advance to ensure that the scant financial resources available were used to support the children as they started school. Having the correct school uniform was important to her so that her boys did not stand 
out as different. The school had a uniform code and expected all children to wear the appropriate uniform. When the uniform was changed, the new uniform was only available through the school at an increased cost. Teagan felt that it was particularly important for Danny to have the correct uniform and so not face questioning by school staff as his challenging behaviour was often triggered by situations involving compliance. Despite Teagan's advance planning, she was compelled to seek financial assistance in order to support a positive start to school. Seeking the assistance reinforced the inability of the family to be self-reliant. In addition, the family's limited finances contributed to Anthony's longer working hours, which again, impacted on the time he had at home with Danny.

\section{Discussion}

All families make decisions and encounter issues and concerns as their children start school. What often differs for families with complex support needs is the nature of the choices available for them, the information or resources they access to inform their decisions, and the confidence with which they approach decisions. These differences are multiplied when the child starting school has special needs.

Families with a child with special needs were surprised to find that placement in a special school was not automatic and that additional funded support for the child in school was also not guaranteed. Navigating different systems and requirements, such as visiting schools and having children assessed, resulted in considerable stress for some families. Despite this stress, parents wanted their children to have positive experiences of school. Many parents adopted advocacy roles and fought for additional support for their children. This was a tiring and frustrating experience, with only partial success for many parents. As in other studies, many parents identified barriers around the availability of support and the processes required to access this (Hess et al., 2006; Janus et al., 2007).

Families successfully navigated the transition to school when they had strong and complementary supports. Many forms of support were available for some, but not all, families. Accessing this support often depended on location and financial resources. Across the geographic regions there was considerable variation in the availability and accessibility of formal support. In some communities, access to professional support was limited and the cost of private support was prohibitive. There was limited evidence of families accessing coordinated support, unless parents themselves, early intervention teachers, or agency staff had actively set out to coordinate services. Not all families with complex support needs had the resources, support, or confidence to achieve such coordination. However, in one instance where early intervention support included strategies to help parents develop these skills, there was clear focus on building family capacity as well as offering support for children.

Coordination of support was further complicated when different services utilised different philosophies and approaches. For example, some services focused on the individual child and supporting his or her specific needs; other services focused on the family as a whole and sought to address multiple, interacting issues. In other instances, families experienced multiple challenges and required diverse support. Where support was contradictory or uncoordinated, parents often reported feelings of confusion and disempowerment.

While many approaches to transition reported a basis drawn from ecological theory, this meant different things in different contexts. At its best, ecological approaches recognised the importance of involving a range of people and contexts in the provision of coordinated support for families and children. However, this ideal was rarely reported. Rather, there was a sense that the processes of transition for individual children and families tended to be subsumed into a system of transition for children with special needs, where many families exercised little agency. Of particular importance for families involved in this study was that 
at the same time as children were making the transition to school, families and children were making a transition to different support services - including their different personnel, approaches, and philosophies - or the transition to no support services. The transition across support services was rarely smooth or continuous. When children started school much of the support that had been available in the prior-to-school years either ceased or changed dramatically. When children and families lost support, negative consequences were seen in terms of children's engagement at school, progression, confidence, and achievement.

Throughout this project, we have sought to focus on the strengths, as well as the challenges within families. There is no doubt that all of the families who participated in the project experienced challenges on many levels. However, it is also the case that each family exhibited remarkable strengths. In some cases, these strengths were not sufficient to overcome the challenges. However, on several occasions, families felt that, with the help of others, they were gradually moving towards achieving their goals. In all cases, one of the goals was for their children to make a positive start to school. In most instances, this was operationalised as children being happy at school. In some cases, the additional goal was for children to have a more positive experience at school than their parents had experienced.

\section{Conclusion}

The transition to school is a time of change and expectation for children, families, and communities. It is recognised as a time of considerable challenge for families with children with special needs. When the situation is further complicated by families themselves having complex support needs, it can be a time of considerable tension and anxiety. Indeed, the interplay of these needs can position families in ways that reinforce, rather than reduce, the difficulties they encounter. Both sets of needs invoke the involvement of a range of professionals and as children make the move to school, families sought both their support and respect. In several instances this was forthcoming; in others, families felt that their knowledge was not valued and that the family, as a whole, was regarded as incapable of assisting the child. Where this support and respect was evident, families demonstrated not only the commitment, but also a growing repertoire of skills to support both themselves and their children as they started school.

Overwhelmingly, families wanted their children to have access to quality educational services where both they and their children felt welcome and supported. The complex support needs of these families underscored this desire: Many families regarded education as the primary means by which their children could have a positive life. All families had aspirations for their children and sought appropriate support for themselves and their children in order to attain these.

\section{References}

Ashman, A., \& Elkins, J. (2005). Educating children with diverse abilities (2nd ed.). Frenchs Forest, NSW: Pearson.

Bernard van Leer Foundation. (2007). Successful transitions: The continuum from home to school. Early Childhood Matters, 107, 23-28. Retrieved from http:/www.bernardvanleer.org/English/Home /Our-publications/Browse_by_series.html?ps_page=1\&getSeries $=4$

Boethel, M. (2004). Readiness: School, family \& community connections. Austin, TX: National Center for Family \& Community Connections with Schools. Retrieved from http://www.sedl.org/connections /resources/readiness-synthesis.pdf

Breen, L. J. (2009). Early childhood service delivery for families living with childhood disability: Disabling families through problematic implicit ideology. Australasian Journal of Early Childhood, 34(4), 14-21. Retrieved from http://www.earlychildhoodaustralia.org.au/australian_journal_of_ early_childhood/australian_journal_of_early_childhood.html 
Bronfenbrenner, U., \& Morris, P. A. (1998). The ecology of developmental processes. In W. Damon \& R. M. Lerner (Eds.), Handbook of child psychology: Theoretical models of human development (5th ed., Vol. 1, pp. 993-1029). New York, NY: Wiley.

Burgess-Limerick, T., \& Burgess-Limerick, R. (1998). Conversational interviews and multiple-case research in psychology. Australian Journal of Psychology, 50(2), 63-70. doi:10.1080 /00049539808257535

Carlson, E., Daley, T., Bitterman, A., Heinzen, H., Keller, B., Markowitz J., \& Riley, J. (2009). Early school transitions and the social behavior of children with disabilities: Selected findings from the Pre-Elementary Education Longitudinal Study. Rockville, MD: Westat. Retrieved from https:// www.peels.org/Docs/Early\%20School\%20Transitions\%20and\%20the\%20Social\%20Behavior\%2 0of $\% 20$ Children $\% 20$ with\%20Disabilities.pdf

Case, S. (2000). Refocusing on the parent: What are the social issues of concern for parents of disabled children? Disability and Society, 15(2), 271-292. doi:10.1080/09687590025676

Charmaz, K. (2008). Grounded theory as an emergent method. In S. N. Hesse-Biber \& P. Leahy (Eds.), Handbook of emergent methods (pp. 155-170). New York, NY: Guildford.

Cowger, C. (1997). Assessing client strengths: Assessment for client empowerment. In D. Saleebey (Ed.), The strengths perspective in social work practice (pp. 59-73). New York, NY: Longman.

Dockett, S., \& Perry, B. (2007). Transitions to school: Perceptions, expectations, experiences. Sydney: UNSW Press.

Dowling, M., \& Dolan, L. (2001). Families with children with disabilities - inequalities and the social model. Disability and Society, 16(1), 21-25. doi:10.1080/713662027

Duncan, N. (2003). Awkward customers? Parents and provision for special educational needs. Disability and Society, 18(3), 341-356. doi:10.1080/0968759032000052905

Farrar, E., Goldfeld, S., \& Moore, T. (2007). School readiness. ARACY topical paper. West Perth, WA: Australian Research Alliance for Children and Youth. Retrieved from http://www.aracy.org.au /publicationDocuments/TOP_School_Readiness_2007.pdf

Forget-Dubois, N., Dionne, G., Lemelin, J.-P., Perusse, D., Tremblay, R. E., \& Boivin, M. (2009). Early child language mediates the relation between home environment and school readiness. Child Development, 80(3), 736-749. doi:10.1111/j.1467-8624.2009.01294.x

Goelman, H. (2008). Three complementary community-based approaches to the early identification of young children at risk for developmental delays/disorders. Infants \& Young Children, 21(4), 306323. doi:10.1097/01.IYC.0000336543.45003.0e

Griebel, W., \& Niesel, R. (2002). Co-constructing transition in kindergarten and school by children, parents and teachers. In H. Fabian \& A-W. Dunlop (Eds.), Transitions in the early years: Debating continuity and progression for young children in early education (pp. 64-75). London, UK: Routledge.

Hair, E., Halle, T., Terry-Humen, E., Lavelle, B., \& Calkins, J. (2006). Children's school readiness in the ECLS-K: Predictions to academic, health, and social outcomes in first grade. Early Childhood Research Quarterly, 21(4), 431-454. doi:10.1016/j.ecresq.2006.09.005

Hess, R. S., Molina, A. M., \& Kozleski, E. B. (2006). Until somebody hears me: Parent voice and advocacy in special educational decision making. British Journal of Special Education, 33(3), 148157. doi:10.1111/j.1467-8578.2006.00430.x

Janus, M., Cameron, R., Lefort, J., \& Kopechanski, L. (2007). Starting kindergarten: What do we know about issues affecting the transition to school for children with special needs? Canadian Journal of Education, 30(3), 628-648. Retrieved from www.csse-scee.ca/csse/cje/

Janus, M., Kopechanski, L., Cameron, R., \& Hughes, D. (2008). In transition: Experiences of parents of children with special needs at school entry. Early Childhood Education Journal, 35(5), 479-485. doi:10.1007/s10643-007-0217-0

Katz, I., Spooner, C., \& valentine, k. (2007). What interventions are effective in improving outcomes for children of families with multiple and complex problems? Perth: Australian Research Alliance for Children and Youth. Retrieved from http://www.sprc.unsw.edu.au/media/File/Report_ARACY ComplexProblems.pdf

Lake, J., \& Billingsley, B. (2000). An analysis of factors that contribute to parent-school conflict in special education. Remedial and Special Education, 21(4), 240-251. doi:10.1177/074193250002100407

Liamputtong, P. (2007). Researching the vulnerable. London, UK: Sage.

McTaggart, P., \& Sanders, M. (2003). The Transition to School Project: Results from the classroom. Australian e-Journal for the Advancement of Mental Health, 2(3). doi:10.5172/jamh.2.3.144 
Miedel, W., \& Reynolds, A. (1999). Parent involvement in early intervention for disadvantaged children: Does it matter? Journal of School Psychology, 37(4), 379-402. Retrieved from www.elsevier.com /locate/jschpsyc

Munford, R., \& Sanders, J. (2003). Making a difference in families: Research that creates change. Sydney: Allen \& Unwin.

New South Wales Department of Education and Training. (2010). Disability programs. Retrieved from http://www.schools.nsw.edu.au /studentsupport/programs/disability.php

Pelletier, J., \& Brent, J. (2002). Parent participation in children's school readiness: The effects of parental self-efficacy, cultural diversity and teacher strategies. International Journal of Early Childhood, 34(1), 45-60. Retrieved from http://www.springer.com/education+\%26+language/journal/13158

Petriwskyj, A. (2010). Diversity and inclusion in the early years. International Journal of Inclusive Education, 14(2), 195-212. doi:10.1080/13603110802504515

Pianta, R. C., \& Cox, M. (Eds.). (1999). The transition to kindergarten. Baltimore, MD: Paul H. Brookes.

Putnam, R. (2000). Bowling alone: The collapse and revival of American community. New York, NY: Touchstone.

Rimm-Kaufman, S. E., \& Pianta, R. C. (2000). An ecological perspective on children's transition to kindergarten: A theoretical framework to guide empirical research. Journal of Applied Developmental Psychology, 21(5), 491-511. Retrieved from http://www.elsevier.com/wps/find /journaldescription.cws home/620199/description

Rogoff, B. (2003). The cultural nature of child development. New York, NY: Oxford.

Russell, F. (2003). The expectations of parents of disabled children. British Journal of Special Education, 30(3), 144-149. Retrieved from http://www.wiley.com/bw/journal.asp?ref=0952-3383

Ryan, S., \& Cole, K. R. (2009). From advocate to activist? Mapping the experience of mothers of children on the autism spectrum. Journal of Applied Research in Intellectual Disabilities, 22(1), 43-53. doi:10.1111/j.1468-3148.2008.00438.x

Sektnan, M., McClelland, M., Acock, A., \& Morrison, F. (2010). Relations between early family risk, children's behavioural regulation, and academic achievement. Early Childhood Research Quarterly, 25(4), 464-479. doi:10.1016/j.ecresq.2010.02.005

Shonkoff, J., Boyce, W., \& McEwen, B. (2009). Neuroscience, molecular biology, and the childhood roots of health disparities: Building a new framework for health promotion and disease prevention. Journal of the American Medical Association, 301(21), 2252-2259. doi:10.1001/jama.2009.754

Smart, D., Sanson, A., Baxter, J., Edwards, B., \& Hayes, A. (2008). Home-to-school for financially disadvantaged children: Final report. Sydney: The Smith Family and Australian Institute of Family Studies. Retrieved from The Smith Family website: http://www.thesmithfamily.com.au /webdata/resources/files/HometoSchool_FullReport_WEB.pdf

Stake, R. (2008). Qualitative case studies. In N. Denzin \& Y. Lincoln (Eds.), Strategies of qualitative inquiry (pp. 119-150). Los Angeles, CA: Sage.

Strauss, A., \& Corbin, J. (1998). Basics of qualitative research: Grounded theory procedures and techniques. Newbury Park, CA: Sage.

Tudball, J., Fisher, K., Sands, T., \& Dowse, L. (2002). Supporting families who have a child with a disability (Social Policy Research Centre Report 1/03). Sydney: University of New South Wales.

Valeo, A. (2003). Special education tribunals in Ontario. International Journal of Special Education, 18(2), 18-30. Retrieved from www.internationaljournalofspecialeducation.com/

Walker, D., Singer, J., Palfrey, J., Orza, M., Wenger, M., \& Butler, J. (1988). Who leaves and who stays in special education: A 2-year follow-up study. Exceptional Children, 54, 393-402. Retrieved from http://www.cec.sped.org/content/NavigationMenu/Publications2/exceptionalchildren/

Wang, M., Mannan, H., Poston, D., Turnbull, A. P., \& Summers, J. A. (2004). Parents' perceptions of advocacy activities and their impact on family quality of life. Research and Practice for Persons with Severe Disabilities, 29(2), 144-155. doi:10.2511/rpsd.29.2.144

Westcott, K., Perry, B., Jones, K., \& Dockett, S. (2003). Parents' transition to school. Journal of Australian Research in Early Childhood Education, 10(2), 26-38. Retrieved from http://www.education.monash.edu.au/research/irecejournal/

Wolery, M. (1999). Children with disabilities in early elementary school. In R. C. Pianta \& M. J. Cox (Eds.), The transition to kindergarten (pp. 253-280). Baltimore, MD: Paul H. Brookes. 


\section{Authors' Note}

Correspondence concerning this article should be addressed to Sue Dockett, Murray School of Education, Charles Sturt University, PO Box 789, Albury NSW 2640, Australia. Email: sdockett@csu.edu.au

This research was supported by the Australian Research Council Grant LP0669546. We wish to acknowledge the expert assistance of our research colleagues Anne Hampshire, Jan Mason, and Virginia Schmeid and express our gratitude to the children and families who participated in the research. 